\title{
Infliximab is more effective than cyclosporine as a rescue therapy for acute severe ulcerative colitis: a retrospective single-center study
}

\section{Marco Le Grazie ${ }^{a}$, Siro Bagnolia, Gabriele Dragonia,b, Saverio Cainic, Vito Annese ${ }^{\mathrm{d}}$, Tommaso Innocentia , Simona Deiana ${ }^{e}$, Natalia Manettif, Stefano Milani ${ }^{\mathrm{a}, \mathrm{b}}$, Andrea Gallia,b, Monica Milla ${ }^{\mathrm{a}}$}

AOU Careggi Hospital, Florence, Italy; Mario Serio University of Florence, Italy; Institute for Oncologic Study, Prevention and Networking, Florence, Italy; Valiant Clinic, Dubai, United Arab Emirates; Ramazzini Hospital, Carpi, AUSL Modena, Italy; San Jacopo Hospital, Pistoia, Usl Centro Toscana, Italy

\section{Abstract}

Background Acute severe ulcerative colitis (ASUC) is a potentially life-threatening disease, and the best option in cases of steroid-refractory disease is still debated. We compared the early- and long-term efficacy and safety of the 2 available "rescue therapies", infliximab (IFX) and cyclosporine (CYS), in this setting.

Methods We retrospectively evaluated patients admitted for ASUC and treated with "rescue therapy". The primary endpoint was early colectomy-free survival (30 days) and colectomy-free survival until the end of follow up. The secondary endpoints were predictors of colectomy and long-term maintenance of the treatment strategy over time.

Results Of 129 patients admitted, 68 received rescue therapy ( 47 with IFX), whereas 7 underwent early colectomy (10.3\%). At 30 days, fewer patients treated with IFX showed a need for colectomy (8.5\% vs. $14.3 \%$ ) compared to those in the CYS group, though the difference was non-significant (odds ratio [OR] 0.69, 95\% confidence interval [CI] 0.10-4.69; $\mathrm{P}=0.47$ ). No severe side effects due to IFX and CYS were observed. During a mean follow up of 40 months, 23 additional patients (37.7\%) underwent colectomy, and the rate was significantly lower in the IFX group (25.6\%) than in the CYS group (66.7\%) (hazard ratio $0.25,95 \% \mathrm{CI} 0.10-0.61 ; \mathrm{P}=0.003$ ). Colectomy-free survival was significantly higher in the IFX group than in the CYS group ( $\mathrm{P}=0.018)$ at 12 months.

Conclusions In our setting, the early outcomes of IFX and CYS for ASUC were comparable. IFX was associated with significantly lower colectomy rates during the observation period and had a similar safety profile to CYS.

Keywords Ulcerative colitis, rescue therapy, anti-tumor necrosis factor, calcineurin inhibitors

Ann Gastroenterol 2021; 35 (1): 1-8

a'IBD Referral Center, Department of Gastroenterology, AOU Careggi Hospital, Florence, Italy (Marco Le Grazie, Siro Bagnoli, Gabriele Dragoni, Tommaso Innocenti, Stefano Milani, Andrea Galli, Monica Milla); 'Gastroenterology Research Unit, Department of Experimental and Clinical Biochemical Sciences "Mario Serio", University of Florence, Italy (Gabriele Dragoni, Stefano Milani, Andrea Galli); ${ }^{\mathrm{c} C . S}$. Epidemiology of Risk Factors and Lifestyle, Institute for Oncologic Study, Prevention and Networking (ISPRO), Florence, Italy (Saverio Caini); 'Valiant Clinic, Dubai, United Arab Emirates (Vito Annese); ${ }^{\mathrm{e} G a s t r o e n t e r o l o g y}$ and Digestive Endoscopy, Ramazzini Hospital, Carpi - AUSL Modena, Modena, Italy (Simona Deiana); ${ }^{\mathrm{f}}$ Gastroenterology and Digestive Endoscopy, San Jacopo Hospital, Pistoia, Usl Centro Toscana, Italy (Natalia Manetti)

\section{Conflict of Interest: None}

Correspondence to: Le Grazie Marco, Department of Gastroenterology, IBD Referral Center, AOU Careggi Hospital, Largo Brambilla 3, 50134, Florence, Italy, e-mail: marcolegrazie89@gmail.com

Received 29 July 2020; accepted 2 November 2020; published online 27 January 2021

DOI: https://doi.org/10.20524/aog.2021.0584

\section{Introduction}

Ulcerative colitis (UC) is still a challenging clinical condition and a potentially life-threatening disease. Severe flares, characterized by an elevated number of bowel movements, bloody stools, and signs and symptoms of a systemic inflammatory response (e.g., fever, tachycardia and elevation of blood markers of inflammation), require hospitalization, nutritional support, and management and prevention of complications. The etiology is unknown, and the pathophysiology appears to be multifactorial, involving genetic and environmental factors that lead to chronic inflammatory damage to the rectum and colon. In this clinical context, intravenous (IV) steroid treatment is the first therapeutic option, but this approach is not effective in $30-40 \%$ of patients, defined as "steroid-refractory" [1]. In these cases, it may be necessary to perform a proctocolectomy [2], a curative approach [3] also associated with potential morbidity and mortality [4]. 
The introduction of cyclosporine (CYS) and infliximab (IFX) as a "rescue therapy" in the setting of steroid-refractory acute severe ulcerative colitis (ASUC) has enabled the avoidance of early colectomy in a significant percentage of patients $[5,6]$. Although the efficacy of CYS as a rescue therapy is well defined [5-7], this drug presents important side effects (e.g., hypomagnesemia, hypertension, seizures, and renal toxicity) that must be taken into account [8].

Among the available anti-tumor necrosis factor (TNF) treatments, IFX is the only one with a demonstrated efficacy in the ASUC setting $[5,6,9]$. This drug is also associated with infectious and possibly neoplastic complications; thus, a proper risk assessment is needed before initiating the treatment $[10,11]$. Additionally, because of the half-life of IFX, an alternate surgical approach (a modified 2- or 3-stage procedure) is recommended [2]; thus, a proper indication for this treatment is necessary. A few prospective trials and retrospective studies have compared IFX and CYS in the context of ASUC rescue therapy and have shown no significant differences in terms of efficacy, safety or colectomy rate [12-17]. However, the debate is still ongoing, because most published studies are multicentric, possibly reflecting different management methodologies, and include limited follow up. Therefore, we aimed to compare the outcomes of IFX and CYS as a rescue therapy for patients with ASUC admitted to our tertiary referral center.

\section{Patients and methods}

\section{Hospital management}

In our retrospective study, all UC cases admitted to the inflammatory bowel disease referral center of the University Hospital Careggi in Florence from January 2008 to December 2017 were evaluated. All patients over 18 years of age affected by ASUC and refractory to IV steroids were included.

At admission, blood and stool tests, planned abdominal $\mathrm{X}$-ray and rectosigmoidoscopy were performed in cases of suspected ASUC to assess possible complications (i.e., toxic megacolon) and comorbidities. Screening for infections and possible contraindications to immunosuppressive treatment was also carried out in the first few days. All patients positive for cytomegalovirus, Clostridioides difficile and other types of infectious colitis were excluded from the analysis. Blood tests included hemoglobin, C-reactive protein (CRP), erythrocyte sedimentation rate (ESR) and albumin. In addition, the CRP/ albumin ratio, which has been suggested as an early predictor of steroid responsiveness, was calculated $[18,19]$.

A severe flare was defined based on Truelove and Witt's criteria [20]. The presence of deep ulcers on endoscopy was also evaluated as a predictor of steroid failure [21].

At admission and during the hospital stay, surgical evaluation was performed to discuss the possible need for colectomy with the patient; colectomy could be proposed as the first treatment if certain clinical factors, such as duration of illness, and/or endoscopic findings (deep ulcers and presence of pseudopolyps), were noticed.

\section{Treatment and follow up}

According to the guidelines of the European Crohn's and Colitis Organisation, patients were treated with IV steroids at a dosage of $1 \mathrm{mg} / \mathrm{kg}$ of body weight, up to a maximum of $60 \mathrm{mg}$ every $24 \mathrm{~h}$ [11]. Steroid refractoriness was defined as a lack of response to a proper dosage after 72-120 h [10]. Treatment with CYS at a dosage of $2 \mathrm{mg} / \mathrm{kg}$ in continuous IV infusion or IFX at a dosage of $5 \mathrm{mg} / \mathrm{kg}$ IV was administered in cases of steroid resistance.

In consideration of the supposed equivalence of the 2 regimens, the choice was based on the existing contraindications to 1 of the 2 drugs (e.g., positive or indefinite QuantiFERON for IFX) and previous therapy (i.e., adverse reactions to previous therapy with thiopurines or IFX). The CYS dosage was titrated based on serum therapeutic levels (range 200-400 $\mu \mathrm{g} / \mathrm{L}$ ) [22]. IV treatment was continued for 14 days, then azathioprine was added (2-2.5 mg/kg per day), and CYS was shifted to an oral formulation at a dose of $4 \mathrm{mg} / \mathrm{kg}$ per day for 3-6 months. Patients treated with IFX were discharged from the hospital after the first or the second induction dose (week 2). The treatment was continued in the outpatient setting according to a standard schedule ( 2 and 6 weeks after the first infusion, then every 8 weeks). No constant combination therapy (IFX and azathioprine) and no accelerated dosing of IFX therapy were administered. For both IFX and CYS treatment, steroids were quickly tapered by reducing by $5 \mathrm{mg}$ /day every 7 days until treatment suspension. In the CYS group, prophylaxis for Pneumocystis jiroveci with cotrimoxazole was administered. Both treatments, CYS and IFX, were evaluated jointly with a surgeon within 7 days to decide whether to continue or move to colectomy. If the patient continued to present significant disease activity (defined by the number of bowel movements, presence of blood in stool, etc.) 5-7 days after the start of rescue treatment, surgical treatment was suggested. No second-line rescue therapy was proposed for the patients included in the study. Patients were commonly assessed at one month after discharge and then periodically followed until the end of the study period, according to clinical conditions and the need for drug dispensation.

\section{Study design and endpoints}

Anthropometric and clinical data of patients were collected. Response to rescue therapy was defined as steroid-refractory ASUC patients who avoided early colectomy (at 30 days). The comparison of early colectomy rates in the two groups (IFX and CYS) was a primary endpoint. During the follow up, patients were classified as non-failures if they continued to take the drug as scheduled (IV IFX or oral azathioprine in the case of CYS treatment) or if they discontinued the scheduled drug because of stable remission of the disease, defined as the absence of new acute flares and by a normal number of bowel movements without rectal bleeding during late follow up. On the other hand, patients were classified as failures if they stopped the therapy for reasons recorded as: a) adverse events; b) switch/swap to other drugs because of loss of response; 
or c) late colectomy due to severe flares. The follow-up time period was calculated from the initiation of rescue therapy to the last follow-up visit in the non-failure group, and to drug discontinuation or surgical treatment in cases of loss of response.

Late colectomy, evaluated in terms of colectomy rates and colectomy-free survival during follow up in the 2 groups, was another primary endpoint. Secondary endpoints were: a) possible predictors of response and need for colectomy; and b) long-term maintenance of the chosen strategy over time.

\section{Statistical analysis}

Chi-square tests and $t$-tests were used to compare the distribution of categorical and continuous variables, respectively, between patients who did or did not undergo colectomy. Laboratory values were also categorized as binary variables using 2 different types of cutoff values: (a) those suggested by the scientific literature [18,23], namely, $11 \mathrm{~g} / \mathrm{dL}$ for hemoglobin, $45.0 \mathrm{mg} / \mathrm{L}$ for CRP, $25 \mathrm{~g} / \mathrm{L}$ for serum albumin, 0.85 for CRP/albumin ratio, and $40.0 \mathrm{~mm} / \mathrm{h}$ for ESR; and (b) "optimal" cutoff values obtained from receiver operating curves (ROCs) using the "nearest" method (which finds the closest point to perfect sensitivity and specificity on the ROC curve). We fitted uni- and multi-variate logistic regression models to identify variables associated with the risk of early colectomy. We then compared the long-term risk of undergoing colectomy after hospital discharge between patients treated with CYS and IFX by conducting univariate Kaplan-Meier survival analysis (using the log-rank test to compare the two curves) and by fitting a multivariable Cox regression model adjusted for sex, age, previous treatment (categorized as experienced vs. naïve), and the presence of deep ulcers. All analyses were performed using STATA version 14 (Stata Corp, College Station, TX, USA). All analyses were 2-sided, with the P-value cutoff for significance set at 0.05 .

\section{Results}

During the ASUC study period, 129 patients were admitted, of whom 68 received rescue therapy because they failed IV steroids. The mean age was 41 years (interquartile range [IQR] 26-52) and $60.29 \%$ of patients were male.

Half of the patients had not previously received immunosuppressive therapy, while the remaining patients had been treated with immunosuppressants (azathioprine or 6-mercaptopurine) or anti-TNFs (adalimumab, golimumab or infliximab). No initial flares of ulcerative colitis were observed.

\section{Early outcomes}

Among 68 patients with steroid-refractory ASUC, 47 $(69.12 \%)$ were treated with IFX and 21 (30.88\%) were treated with CYS. As shown in Table 1, neither demographic nor clinical differences between the 2 groups were observed.

Early colectomy within 30 days was performed in 7 of 68 patients (10.3\%), 3 in the CYS group and 4 in the IFX group. This difference was not statistically significant (14.3\% CYS vs. $8.5 \%$ IFX, odds ratio [OR] $0.56,95 \%$ confidence interval [CI] 0.11-2.75; $\mathrm{P}=0.47$ ) (Table 2). No significant adverse events or major infectious events due to the 2 treatments were observed. Rescue therapy was not suspended in any patients.

Hemoglobin, ESR, CRP, albumin and the CRP/albumin ratio were analyzed as both continuous and categorical data. No demographic or clinical characteristics were correlated with a higher risk of early colectomy in univariate analysis for both categorical and continuous variables (Table 2). When parameters were compared using cutoffs obtained from ROCs, an elevated ESR (cutoff $47, \mathrm{P}=0.061$ ) and $\mathrm{CRP} /$ albumin ratio (cutoff 1.06, $\mathrm{P}=0.089$ ) showed a non-significant correlation with early colectomy (Table 3 ). In particular, the risk of early colectomy in patients with an elevated ESR was 6-fold higher than that in patients with a lower ESR (OR 6.46, 95\%CI 0.7357.5; $\mathrm{P}=0.094)$.

Table 1 Demographic and clinical characteristics of patients

\begin{tabular}{|c|c|c|c|}
\hline Characteristics & Infliximab & Cyclosporine & P-value \\
\hline \multicolumn{4}{|l|}{ Sex } \\
\hline Male & $30(63.8 \%)$ & $11(52.4 \%)$ & \multirow[t]{2}{*}{0.4276} \\
\hline Female & $17(36.2 \%)$ & $10(47.6 \%)$ & \\
\hline $\begin{array}{l}\text { Age, years } \\
\text { - mean (IQR) }\end{array}$ & $40(26-52)$ & $42(25-63)$ & 0.6522 \\
\hline $\begin{array}{l}\mathrm{CRP}, \mathrm{mg} / \mathrm{L} \\
- \text { mean }(\mathrm{SD})\end{array}$ & $60.0(52.8)$ & $53.8(51.3)$ & 0.6533 \\
\hline$<45$ & $25(53.2 \%)$ & $12(57.1 \%)$ & \multirow[t]{2}{*}{0.7980} \\
\hline$\geq 45$ & $22(46.8 \%)$ & $9(42.9 \%)$ & \\
\hline $\begin{array}{l}\text { ESR, mm/h } \\
\text { - mean (SD) }\end{array}$ & $49.2(23.7)$ & $43.7(20.6)$ & 0.3806 \\
\hline$<40$ & $16(39.0 \%)$ & $9(60.0 \%)$ & \multirow[t]{2}{*}{0.2270} \\
\hline$\geq 40$ & $25(61.0 \%)$ & $6(40.0 \%)$ & \\
\hline $\begin{array}{l}\text { Hemoglobin, g/dL - } \\
\text { mean (SD) }\end{array}$ & $11.4(2.0)$ & $11.5(2.2)$ & 0.8546 \\
\hline$<11$ & $20(43.5 \%)$ & $9(42.9 \%)$ & \multirow[t]{2}{*}{1.0000} \\
\hline$\geq 11$ & $26(56.5 \%)$ & $12(57.1 \%)$ & \\
\hline $\begin{array}{l}\text { Albumin, g/dL } \\
\text { - mean (SD) }\end{array}$ & $29.0(5.8)$ & $27.7(6.1)$ & \multirow[t]{3}{*}{0.7668} \\
\hline$<25$ & $13(28.9 \%)$ & $6(33.3 \%)$ & \\
\hline$\geq 25$ & $32(71.1 \%)$ & $12(66.7 \%)$ & \\
\hline $\begin{array}{l}\text { CRP/albumin ratio - } \\
\text { mean (SD) }\end{array}$ & $2.5(2.4)$ & $1.8(1.6)$ & 0.2606 \\
\hline$<0.85$ & $13(23.6 \%)$ & $7(38.9 \%)$ & \multirow[t]{2}{*}{0.5513} \\
\hline$\geq 0.85$ & $32(76.4 \%)$ & $11(61.1 \%)$ & \\
\hline \multicolumn{4}{|l|}{ Previous therapies } \\
\hline Naïve & $21(44.7 \%)$ & $13(61.9 \%)$ & \multirow[t]{2}{*}{0.2938} \\
\hline Experienced & $26(55.3 \%)$ & $8(38.1 \%)$ & \\
\hline \multicolumn{4}{|l|}{ Deep ulcers } \\
\hline No & $28(56.0 \%)$ & $6(40.0 \%)$ & \multirow[t]{2}{*}{0.0620} \\
\hline Yes & $12(44.0 \%)$ & $9(60.0 \%)$ & \\
\hline
\end{tabular}

SD, standard deviation, CRP, C-reactive protein; ESR, erythrocyte sedimentation rate 
Table 2 Early outcomes by univariate analysis

\begin{tabular}{|c|c|c|c|c|c|}
\hline Categorical data n (\%) & Early remission & Early colectomy & P-value & Univariate OR $(95 \% \mathrm{CI})$ & P-value \\
\hline $\begin{array}{l}\text { Sex } \\
\text { Male } \\
\text { Female }\end{array}$ & $\begin{array}{l}37(90.2 \%) \\
24(88.9 \%)\end{array}$ & $\begin{array}{c}4(9.8 \%) \\
3(11.1 \%)\end{array}$ & 0.857 & $1.16(0.24-5.63)$ & 0.857 \\
\hline $\begin{array}{l}\text { Previous therapies } \\
\text { Naïve } \\
\text { Experienced }\end{array}$ & $\begin{array}{l}32(86.5 \%) \\
29(93.5 \%)\end{array}$ & $\begin{array}{c}5(13.5 \%) \\
2(6.5 \%)\end{array}$ & 0.340 & $0.44(0.08-2.45)$ & 0.350 \\
\hline $\begin{array}{l}\text { CRP, mg/L } \\
\quad<45 \\
\geq 45\end{array}$ & $\begin{array}{l}34(91.1 \%) \\
27(87.1 \%)\end{array}$ & $\begin{array}{c}3(8.1 \%) \\
4(12.9 \%)\end{array}$ & 0.517 & $1.68(0.35-8.15)$ & 0.520 \\
\hline $\begin{array}{l}\text { ESR, } \mathrm{mm} / \mathrm{h} \\
\quad<40 \\
\geq 40\end{array}$ & $\begin{array}{l}24(96.0 \%) \\
30(83.3 \%)\end{array}$ & $\begin{array}{c}1(4.0 \%) \\
6(16.7 \%)\end{array}$ & 0.127 & $4.80(0.54-42.63)$ & 0.159 \\
\hline $\begin{array}{l}\text { Hemoglobin, g/dL } \\
\quad<11 \\
\quad \geq 11\end{array}$ & $\begin{array}{l}24(82.8 \%) \\
36(94.7 \%)\end{array}$ & $\begin{array}{c}5(17.2 \%) \\
2(5.2 \%)\end{array}$ & 0.112 & $0.27(0.05-1.49)$ & 0.132 \\
\hline $\begin{array}{l}\text { Albumin, g/dL } \\
\quad<25 \\
\geq 25\end{array}$ & $\begin{array}{l}15(79.0 \%) \\
41(93.2 \%)\end{array}$ & $\begin{array}{l}4(21 \%) \\
3(6.8 \%)\end{array}$ & 0.099 & $0.27(0.05-1.37)$ & 0.115 \\
\hline $\begin{array}{l}\text { CRP/albumin } \\
\quad<0.85 \\
\geq 0.85\end{array}$ & $\begin{array}{l}19(95.0 \%) \\
37(86.0 \%)\end{array}$ & $\begin{array}{c}1(5.0 \%) \\
6(14.0 \%)\end{array}$ & 0.293 & $3.08(0.35-27.48)$ & 0.313 \\
\hline $\begin{array}{l}\text { Deep ulcers } \\
\text { No } \\
\text { Yes }\end{array}$ & $\begin{array}{l}34(91.9 \%) \\
21(91.3 \%)\end{array}$ & $\begin{array}{l}3(8.1 \%) \\
2(8.7 \%)\end{array}$ & 0.936 & $1.08(0.17-7.00)$ & 0.936 \\
\hline $\begin{array}{l}\text { Rescue therapies } \\
\text { CYS } \\
\text { IFX }\end{array}$ & $\begin{array}{l}18(85.7 \%) \\
43(91.5 \%)\end{array}$ & $\begin{array}{c}3(14.3 \%) \\
4(8.5 \%)\end{array}$ & 0.469 & $0.56(0.11-2.75)$ & 0.474 \\
\hline Continuous data & Early remission & Early colectomy & P-value & Univariate OR $(95 \% \mathrm{CI})$ & P-value \\
\hline Age, years (IQR) & $40(26-52)$ & $45(27-64)$ & 0.442 & $1.02(0.97-1.06)$ & 0.438 \\
\hline CRP, mg/L (SD) & $58.0(54.6)$ & $58.1(36.7)$ & 0.996 & $1.00(0.99-1.02)$ & 0.996 \\
\hline $\mathrm{ESR}, \mathrm{mm} / \mathrm{h}(\mathrm{SD})$ & $46.1(22.2)$ & $57.9(29.2)$ & 0.206 & $1.02(0.99-1.05)$ & 0.210 \\
\hline Hemoglobin, g/dL (SD) & $11.5(2.0)$ & $10.4(2.6)$ & 0.173 & $0.77(0.52-1.13)$ & 0.179 \\
\hline Albumin, g/dL (SD) & $29.0(5.8)$ & $25.8(7.6)$ & 0.187 & $0.92(0.81-1.04)$ & 0.192 \\
\hline CRP/albumin (SD) & $2.2(2.2)$ & $2.9(2.8)$ & 0.483 & $1.12(0.82-1.54)$ & 0.479 \\
\hline
\end{tabular}

OR, odds ratio; CI, confidence interval; IQR, interquartile range; SD, standard deviation; tp., therapy; CRP, C-reactive protein; ESR, erythrocyte sedimentation rate; CYS, cyclosporine; IFX, infliximab

In multivariate analysis, none of the demographic and clinical characteristics except for ESR were significantly associated with the occurrence of early colectomy. Analysis based on cutoffs from the ROC curve showed an elevated ESR to be significantly related to early colectomy when CRP and albumin were evaluated separately (OR 17.37, 95\%CI 1.05-287.44; $\mathrm{P}=0.046$ ). Furthermore, patients with an elevated ESR had 10-fold greater odds of early colectomy (OR 10.21, 95\%CI 0.71-147.15; $\mathrm{P}=0.088$ ) in a regression model that included the $\mathrm{CRP} /$ albumin ratio as a covariate instead of considering CRP and albumin separately.

\section{Late outcomes}

The mean follow-up time was 40 months (IQR 13-68). During the follow up, a total of 34 failures were observed
(55.7\%), 12 in the CYS group (66.7\%) and 22 in the IFX group (52.5\%; $\mathrm{P}=0.36)$. Failures occurred on average after 20 months (IQR 6-26), specifically after 20 months (IQR 3-32) in the CYS group and after 19 months (IQR 8-26) in the IFX group ( $\mathrm{P}=0.96)$. Among the 12 failures on CYS, 9 patients underwent colectomy directly, whereas a switch to other drugs was attempted without success in 3 patients.

The 22 failures in the IFX group consisted of 8 failures because of late adverse drug reactions, and only 1 of these patients underwent colectomy; 14 failures were due to loss of response, and 4 of these patients successfully switched to other biologic drugs while 10 underwent colectomy.

No differences in terms of failure rates were observed between the 2 groups at the end of the follow up in both univariate (hazard ratio [HR] 0.72, 95\%CI 0.35-1.47; $\mathrm{P}=0.366$ ) and multivariate (HR 0.65, 95\%CI 0.30-1.39; $\mathrm{P}=0.264$ ) 
Table 3 Early outcomes by univariate analysis with optimal cutoffs

\begin{tabular}{|c|c|c|c|c|c|}
\hline Categorical data n (\%) & Early remission & Early colectomy & P-value & Univariate OR $(95 \% \mathrm{CI})$ & P-value \\
\hline $\begin{array}{l}\text { CRP, mg/L } \\
\quad<35 \\
\geq 35\end{array}$ & $\begin{array}{l}32(94.1 \%) \\
29(85.3 \%)\end{array}$ & $\begin{array}{c}2(5.9 \%) \\
5(14.7 \%)\end{array}$ & 0.231 & $2.76(0.50-15.33)$ & 0.246 \\
\hline $\begin{array}{l}\text { ESR, } \mathrm{mm} / \mathrm{h} \\
\quad<47 \\
\geq 47\end{array}$ & $\begin{array}{l}28(96.5 \%) \\
26(81.2 \%)\end{array}$ & $\begin{array}{c}1(3.5 \%) \\
6(18.8 \%)\end{array}$ & 0.061 & $6.46(0.73-57.35)$ & 0.094 \\
\hline $\begin{array}{l}\text { Hemoglobin, g/dL } \\
\quad<12.4 \\
\quad \geq 12.4\end{array}$ & $\begin{array}{l}36(87.8 \%) \\
24(92.3 \%)\end{array}$ & $\begin{array}{c}5(12.2 \%) \\
2(7.7 \%)\end{array}$ & 0.557 & $0.60(0.11-3.35)$ & 0.560 \\
\hline $\begin{array}{l}\text { Albumin, g/dL } \\
\quad<31.2 \\
\geq 31.2\end{array}$ & $\begin{array}{l}34(89.5 \%) \\
22(88.0 \%)\end{array}$ & $\begin{array}{l}4(10.5 \%) \\
3(12.0 \%)\end{array}$ & 0.856 & $1.16(0.24-5.68)$ & 0.856 \\
\hline $\begin{array}{l}\text { CRP/albumin } \\
\quad<1.06 \\
\geq 1.06\end{array}$ & $\begin{array}{l}27(96.4 \%) \\
29(82.9 \%)\end{array}$ & $\begin{array}{c}1(3.6 \%) \\
6(17.1 \%)\end{array}$ & 0.089 & $5.59(0.63-49.46)$ & 0.122 \\
\hline
\end{tabular}

OR, odds ratio; CI, confidence interval; $C R P$, C-reactive protein; $E S R$, erythrocyte sedimentation rate

analyses. Medication failure-free survival evaluated with Kaplan-Meier survival analysis showed no differences between the two groups ( $\mathrm{P}=0.360$, Fig. 1$)$. An analysis of data obtained after 12 months of follow up showed that patients in the IFX group had approximately half of the rate of failures ( 9 failures, $21.4 \%$ ) of patients in the CYS group ( 8 failures, $44.4 \% ; \mathrm{P}=0.07$ ), which was confirmed in univariate analysis (HR $0.38,95 \% \mathrm{CI}$ $0.15-0.99 ; \mathrm{P}=0.049$ ), while the difference was not statistically significant in the multivariate analysis ( $\mathrm{HR} \mathrm{0.36,95 \% \textrm {CI }}$ 0.13-1.03; $\mathrm{P}=0.058)$. On the other hand, no differences were observed after 24 months of follow up (data not shown).

In total, 23 patients $(37.7 \%)$ underwent colectomy during late follow up: $12(66.7 \%)$ in the CYS group and $11(25.6 \%)$ in the IFX group $(\mathrm{P}=0.003)$. Furthermore, the risk of late colectomy was lower in the IFX group in both univariate (HR $0.29,95 \% \mathrm{CI} 0.13-0.67 ; \mathrm{P}=0.003)$ and multivariate analyses ( $\mathrm{HR}$ $0.25,95 \%$ CI $0.10-0.61 ; \mathrm{P}=0.003)$, as shown in Table 4 . The rate of late colectomies was lower in the IFX group in multivariate analysis, both at 12 months ( $11.9 \%$ vs. $44.4 \%$, HR $0.18,95 \% \mathrm{CI}$ $0.05-0.64 ; \mathrm{P}=0.008)$ and at 24 months $(25.0 \%$ vs. $56.3 \%$, HR $0.24,95 \%$ CI $0.09-0.69 ; \mathrm{P}=0.008$ ).

In addition, colectomy-free survival rates evaluated with Kaplan-Meier survival analysis differed significantly between the CYS and IFX groups ( $\mathrm{P}=0.018$, Fig. 2). Colectomy-free survival rates for the CYS and IFX groups were $55.5 \%$ vs. $90.5 \%$ at 12 months, $49.4 \%$ vs. $77.0 \%$ at 24 months and $49.4 \%$ vs. $69.2 \%$ at 60 months, respectively. Regarding predictors of late colectomy, female sex was associated with a lower risk ( $25.0 \%$ vs. $45.9 \%$, HR 0.29, 95\%CI 0.09-0.94; $\mathrm{P}=0.039$ ). Age, deep ulcers at the time of rescue therapy and previous therapies did not appear to be predictors of late colectomy.

\section{Discussion}

ASUC still represents a challenge for gastroenterologists, particularly in the case of IV steroid failure. "Rescue

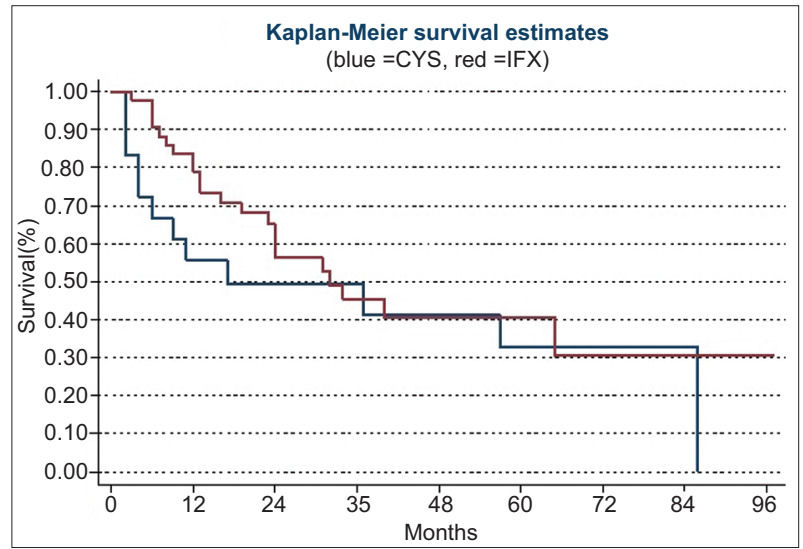

Figure 1 Medication failure-free survival evaluated with Kaplan-Meier survival analysis according to the treatment given at inclusion

CYS, cyclosporin vs. IFX, infliximab $(P=0.360)$ at 12 months: $55.5 \%$ vs. 78.7\%; at 24 months: $49.3 \%$ vs. $56.2 \%$; and at 60 months: $32.9 \%$ vs. $40.6 \%$

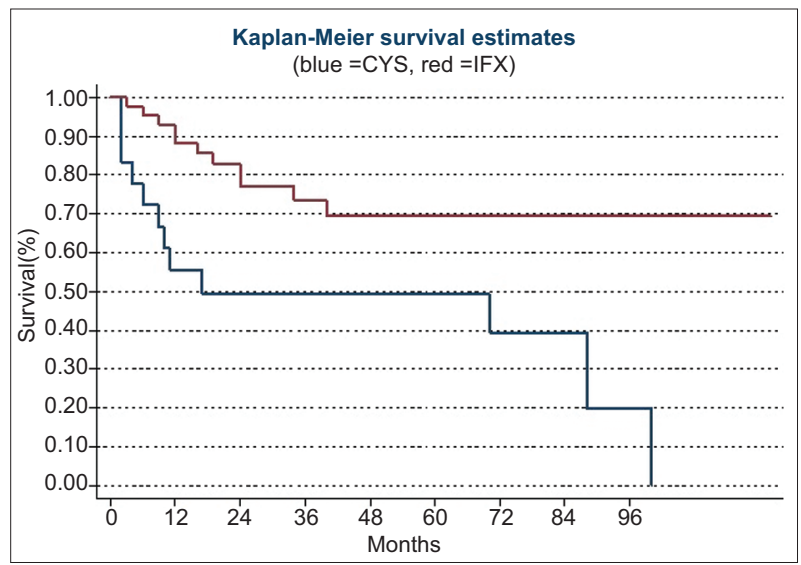

Figure 2 Colectomy-free survival was evaluated with Kaplan-Meier survival analysis according to the treatment given at inclusion

CYS, cyclosporine vs. IFX, infliximab $(P=0.018)$ at 12 months: $55.5 \%$ vs. 90.5\%; at 24 months: $49.4 \%$ vs. $77.0 \%$; and at 60 months: $49.4 \%$ vs. $69.2 \%$ 
6 M. Le Grazie et al

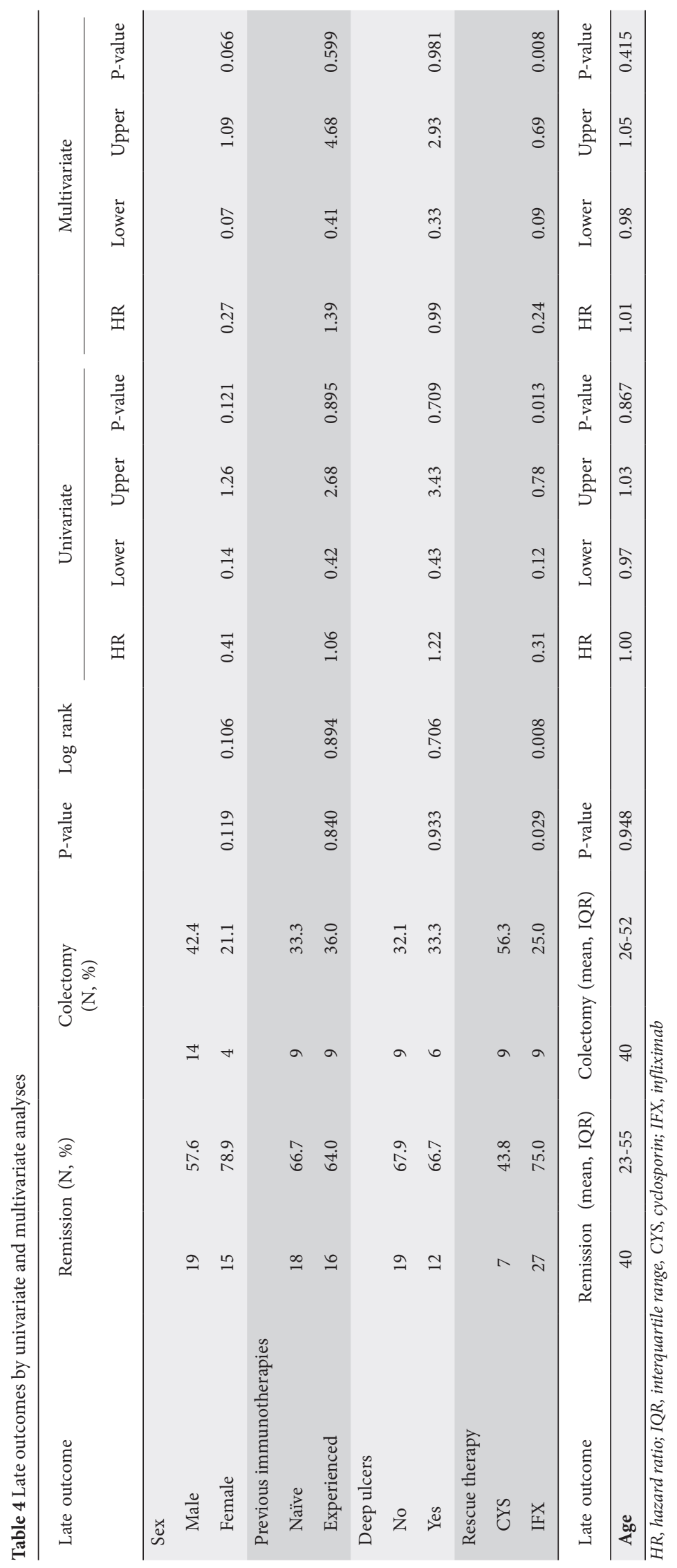


therapy" with either IFX or CYS is the only available drug treatment option in these circumstances, but colectomy is still unavoidable in a significant number of cases. While we wait for new pharmacological options, there is currently no clear indication about which drug is preferable because of the paucity of controlled trials and long-term follow ups. Consequently, treatment choices are mainly based on local expertise, drug availability and the evaluation of possible contraindications.

In our study, the main result was that IFX reduced the colectomy rate during the follow up; this was already suggested at the first month and became more evident (and achieved statistical significance) after 12 months and until the end of follow up (122 months).

Although the cohort was not randomized and no propensity score correction was applied, no other clinical characteristics seemed to clearly influence this outcome except for male sex, which appears to be a risk factor for late colectomy. In particular, no statistically significant difference in terms of previous treatments, age, laboratory findings or colonic deep ulcers detected during ASUC was observed between the IFX and CYS groups. Our results confirm those already reported in other non-randomized studies [15,16], although in the available randomized trials, no differences between IFX and CYS in rescue therapy were found $[12,14]$ after up to 5 years of follow up [13]. Furthermore, it is also interesting to point out the superior efficacy of IFX during the first 12 months of follow up, which could indicate the greater efficacy of this drug for switching off the inflammatory response that characterizes ASUC.

With regard to possible predictors of colectomy, only an elevated ESR was associated with an increased risk of early colectomy and male sex was associated with an increased risk for late colectomy based on multivariate analysis. Notably, however, we found no significant differences in terms of ESR values and sex between patients treated with CYS or IFX. Nevertheless, these results do not accurately reflect what has been previously reported in the literature and may have been influenced by the small statistical sample examined. Data on the influence of sex on disease severity are conflicting in the literature, and commonly no difference has been reported regarding the incidence of colectomy [24,25]. In contrast, an higher incidence of colectomy has been shown in female patients affected by steroid-refractory ASUC [26]. These discrepancies may be related to patient selection and sample size. Future prospective studies should be performed to help clarify these discrepancies.

With respect to safety, we did not observe any adverse events. Adverse events during late follow up were not evaluated further because the clinical settings of the 2 groups were clearly different.

An interesting aspect of rescue therapy for ASUC is related to healthcare costs. The recent introduction of IFX biosimilars has led to a substantial decrease in the cost of this drug, which was an initial barrier to its use in some countries. On the other hand, the need to achieve and maintain adequate serum levels of CYS requires continuous 24-h IV administration, resulting in unavoidable hospitalization for at least 7 days, with a significant impact on the cost of management. In this study, we did not directly evaluate such pharmacoeconomic aspects, but we can assume that the reduced cost and shorter duration of hospitalization with IFX might be favorable and associated with better long-term outcomes.

Our study had some limitations: first, its retrospective design; and second, the relatively small sample size due to monocentric inclusion. In contrast, the strength of the study was its prolonged follow up and the homogenous management and interaction among gastroenterologists and surgeons of our unit.

In conclusion, in our cohort, IFX seems to be more effective than CYS for avoiding colectomy. This advantage was already detectable after one month and consistently and significantly confirmed during a follow up of up to 90 months. We identified an elevated ESR as a possible risk factor for early colectomy and male sex as a possible risk factor for late colectomy, which need further confirmation. Both medications had a similar safety profile in the context of rescue therapy, and no severe adverse events were reported.

\section{Summary Box}

\section{What is already known:}

- Rescue therapy for steroid-refractory acute severe ulcerative colitis is still a topic of debate

- The European Crohn's and Colitis Organisation guidelines suggest cyclosporine or infliximab as a rescue therapy in this clinical context

- No definitive indications are yet available regarding the preferable choice between the 2 drugs

\section{What the new findings are:}

- Infliximab and cyclosporine treatments were related to similar early colectomy rates in this study

- Infliximab showed significantly lower late colectomy rates than cyclosporine

- Infliximab and cyclosporine showed similar safety profiles

\section{References}

1. Turner D, Walsh CM, Steinhart AH, Griffiths AM. Response to corticosteroids in severe ulcerative colitis: a systematic review of the literature and a meta-regression. Clin Gastroenterol Hepatol 2007;5:103-110.

2. Magro F, Gionchetti P, Eliakim R, et al; European Crohn's and Colitis Organisation [ECCO]. Third European Evidence-based Consensus on Diagnosis and Management of Ulcerative Colitis. Part 1: Definitions, Diagnosis, Extra-intestinal Manifestations, Pregnancy, Cancer Surveillance, Surgery, and Ileo-anal Pouch Disorders. J Crohns Colitis 2017;11:649-670. 
3. Smith LE. Surgical therapy in ulcerative colitis. Gastroenterol Clin North Am 1989;18:99-110.

4. de Silva S, Ma C, Proulx MC, et al. Postoperative complications and mortality following colectomy for ulcerative colitis. Clin Gastroenterol Hepatol 2011;9:972-980.

5. Harbord M, Eliakim R, Bettenworth D, et al; European Crohn's and Colitis Organisation [ECCO]. Third European Evidence-based Consensus on Diagnosis and Management of Ulcerative Colitis. Part 2: Current Management. J Crohns Colitis 2017;11:769-784.

6. Kornbluth A, Sachar DB; Practice Parameters Committee of the American College of Gastroenterology. Ulcerative colitis practice guidelines in adults: American College Of Gastroenterology, Practice Parameters Committee. Am J Gastroenterol 2010;105:501523; quiz 524.

7. Lichtiger S, Present DH, Kornbluth A, et al. Cyclosporine in severe ulcerative colitis refractory to steroid therapy. $N$ Engl J Med 1994;330:1841-1845.

8. Graham RM. Cyclosporine: mechanisms of action and toxicity. Cleve Clin J Med 1994;61:308-313.

9. Rutgeerts P, Sandborn WJ, Feagan BG, et al. Infliximab for induction and maintenance therapy for ulcerative colitis. $N$ Engl $J$ Med 2005;353:2462-2476.

10. Dulai PS, Siegel CA. The risk of malignancy associated with the use of biological agents in patients with inflammatory bowel disease. Gastroenterol Clin North Am 2014;43:525-541.

11. Dulai PS, Thompson KD, Blunt HB, Dubinsky MC, Siegel CA. Risks of serious infection or lymphoma with anti-tumor necrosis factor therapy for pediatric inflammatory bowel disease: a systematic review. Clin Gastroenterol Hepatol 2014;12:1443-1451; quiz e88-e89.

12. Laharie D, Bourreille A, Branche J, et al. Ciclosporin versus infliximab in patients with severe ulcerative colitis refractory to intravenous steroids: a parallel, open-label randomised controlled trial. Lancet 2012;380:1909-1915.

13. Laharie D, Bourreille A, Branche J, et al; Groupe d'Etudes Thérapeutiques des Affections Inflammatoires Digestives. Longterm outcome of patients with steroid-refractory acute severe UC treated with ciclosporin or infliximab. Gut 2018;67:237-243.

14. Williams JG, Alam MF, Alrubaiy L, et al. Infliximab versus ciclosporin for steroid-resistant acute severe ulcerative colitis (CONSTRUCT): a mixed methods, open-label, pragmatic randomised trial. Lancet Gastroenterol Hepatol 2016;1:15-24.
15. Kim EH, Kim DH, Park SJ, et al. Infliximab versus cyclosporine treatment for severe corticosteroid-refractory ulcerative colitis: a Korean, retrospective, single center study. Gut Liver 2015;9:601-606.

16. Mocciaro F, Renna S, Orlando A, et al. Cyclosporine or infliximab as rescue therapy in severe refractory ulcerative colitis: early and long-term data from a retrospective observational study. J Crohns Colitis 2012;6:681-686.

17. Narula N, Marshall JK, Colombel JF, et al. Systematic review and meta-analysis: infliximab or cyclosporine as rescue therapy in patients with severe ulcerative colitis refractory to steroids. Am J Gastroenterol 2016;111:477-491.

18. Gibson DJ, Hartery K, Doherty J, et al. CRP/albumin ratio: an early predictor of steroid responsiveness in acute severe ulcerative colitis. J Clin Gastroenterol 2018;52:e48-e52.

19. Choy MC, Seah D, Gorelik A, et al. Predicting response after infliximab salvage in acute severe ulcerative colitis. J Gastroenterol Hepatol 2018;33:1347-1352.

20. D'Haens G, Sandborn WJ, Feagan BG, et al. A review of activity indices and efficacy end points for clinical trials of medical therapy in adults with ulcerative colitis. Gastroenterology 2007;132:763-786.

21. Allez M, Lémann M. Role of endoscopy in predicting the disease course in inflammatory bowel disease. World J Gastroenterol 2010;16:2626-2632.

22. Van Assche G, D’Haens G, Noman M, et al. Randomized, double-blind comparison of $4 \mathrm{mg} / \mathrm{kg}$ versus $2 \mathrm{mg} / \mathrm{kg}$ intravenous cyclosporine in severe ulcerative colitis. Gastroenterology 2003;125:1025-1031.

23. Deiana S, Bagnoli S, Manetti N, et al. Outcome of acute severe ulcerative colitis in patients previously exposed to immunosuppressive therapy. Dig Liver Dis 2016;48:1432-1437.

24. Bábíčková J, Tóthová, Lengyelová E, et al. Sex differences in experimentally induced colitis in mice: a role for estrogens. Inflammation 2015;38:1996-2006.

25. Gonzalez-Lama Y, Fernandez-Blanco I, Lopez-SanRoman A, et al; Group for the Study of Inflammatory Bowel Diseases from Madrid. Open-label infliximab therapy in ulcerative colitis: a multicenter survey of results and predictors of response. Hepatogastroenterology 2008;55:1609-1614.

26. Nasuno M, Miyakawa M, Tanaka H, Motoya S. Short- and longterm outcomes of infliximab treatment for steroid-refractory ulcerative colitis and related prognostic factors: a single-center retrospective study. Digestion 2017;95:67-71. 